\title{
Study on Three-phase Foam for Preventing Spontaneous Combustion of Coal in Goaf
}

\author{
QIN BO-TAO, WANG DE-MING, and REN WAN-XING \\ School of Mineral and Safety Engineering \\ China University of Mining and Technology \\ Xuzhou, Jiangsu 221008, China
}

\begin{abstract}
To enhance the efficiency and economy of mine fire control, the technology of threephase foam for preventing spontaneous combustion of coal in goaf is developed here. The producing flow of three-phase foam and main technical parameters are introduced briefly. Chemical dynamics equation was set up. According to controlling parameters in the equation: the reactant concentration of $\mathrm{C}$ and $\mathrm{O}_{2}$, the temperature $(T)$ of coal and surroundings, the hole rate $(\varepsilon)$ of goaf, etc, the mechanism of three-phase foam for preventing spontaneous combustion of coal in goaf was studied. By the application of three-phase foam in workface $\mathrm{N}_{2} 703$ of Daxing coal mine, which had been high temperature and fire point, the change on concentration of $\mathrm{CO}$ and $\mathrm{O}_{2}$ were contrasted in sampling gas and temperature in goaf. It had effectively prevented the fire. The result showed that the effect of three-phase foam for preventing spontaneous combustion of coal in goaf was excellent, and it is a new technology for mine fire prevention and with good prospect.
\end{abstract}

KEYWORDS: three-phase foam, spontaneous combustion of coal, goaf

\section{NOMENCLATURE LISTING}

\begin{tabular}{llll}
$C_{1}$ & quantity of coal & $Q_{1}$ & heat absorbed by slurry $(\mathrm{J})$ \\
$C_{2}$ & oxygen concentration $\left(\mathrm{mol} / \mathrm{m}^{3}\right)$ & $Q_{2}$ & heat absorbed by evaporation $(\mathrm{J})$ \\
$C_{p}$ & specific heat & $q$ & thermal release rate $\left(\mathrm{J} /\left(\mathrm{m}^{3} \cdot \mathrm{s}\right)\right)$ \\
$E$ & active energy $(\mathrm{J} / \mathrm{mol})$ & $R$ & constant of gas \\
$k$ & a constant of reactive rate & $T$ & temperature of coal $(\mathrm{K})$ \\
$k_{0}$ & a factor of frequency & $T_{1}$ & initial temperature $(\mathrm{K})$ \\
$M_{1}$ & mass of slurry $(\mathrm{kg})$ & $T_{2}$ & finally temperature $(\mathrm{K})$ \\
$M_{2}$ & mass of water $(\mathrm{kg})$ & $V$ & rate of reaction $\left(\mathrm{mol} /\left(\mathrm{m}^{3} \cdot \mathrm{s}\right)\right)$ \\
$m$ & index of reaction & \multicolumn{6}{c}{ Greek } & \\
$n$ & index of reaction & $\varepsilon$ & hole ratio \\
$Q$ & released heat $(\mathrm{J})$ & $\gamma$ & evaporation heat $(\mathrm{kJ} / \mathrm{kg})$
\end{tabular}

\section{INTRODUCTION}

In the recent years, the technology of fully-mechanized top-coal caving mining has been widely used in China. So the production and benefits of coal have been developed rapidly. However, because of higher falling height, more float coal and serious air leakage, the spontaneous combustion of coal in goaf occurs frequently. It is one of the major natural hazards that restricts the safe mining and development in mines. The main principle of preventing spontaneous combustion of coal is to separate the coal from the air. There are many technologies, such as grouting, spraying inhibitors and injecting inert 
gases, which were adopted widely all over the world to prevent spontaneous combustion of coal [1,2]. These technologies play an important role in the protection of safe production of mine, but there are some problems with them. For example, grouting with mud or fly ash can not cover the coal uniformly and reach to the top position; inert gases are prone to diffuse with air leakage and cannot stay longer in the injecting area; inhibitors can rust the equipment and is harmful to the workers. Based on the present technologies, three-phase foam for preventing spontaneous combustion of coal in goaf is developed. It fully overcomes the above disadvantages and enhances the efficiency of mine fire control.

After adding foaming agent and nitrogen into slurry and mixing them up by stirrer, a multiphase system is formed, in which the granules of mud or fly ash adhere to exterior of the foam steadily. It is called as three-phase foam. It is composed of solid noncombustible (mud or fly ash), $\mathrm{N}_{2}$, water and surfactant. As a material for preventing spontaneous combustion of coal, it has many advantages. For example, it can distribute the slurry evenly and avoid loss of the slurry; it can fill the whole area and pile up to cover the top coal in goaf, and so on.

The technology of three-phase foam has been applied in many coal mines. It effectively prevented spontaneous combustion of coal which happened in Yaoqiao Coal Mine, Chaili Coal Mine, Laohutai Coal Mine, Daxing Coal Mine, and so on. It successfully extinguished the large area fire caused by gas explosion in goaf in BaiJigou Coal Mine. The results of application showed that the technology of three-phase foam is with remarkably economic and social benefit for mine fire control.

\section{PRODUCING FLOW AND MAIN TECHNICAL PARAMETERS OF THREE- PHASE FOAM [3,4]}

The following is the flow chart for producing of three phase foam (Fig. 1). Firstly, appropriate concentration of mixed aqueous slurry was prepared by a proportion of water and ash fly or mud in the slurry-making station; Secondly, the prepared slurry was transported into the pipe by pressure pump and the foaming agent was poured into the pipe by measurable screw pump, then the slurry and the foaming agent were fully mixed in the mixing implement and flowed into the foaming generator; Thirdly, nitrogen gas was sucked into the foaming generator by the other pipe; Finally, three phase foam was formed through the reciprocity of nitrogen gas and slurry including water, fly ash or mud and foaming agent.

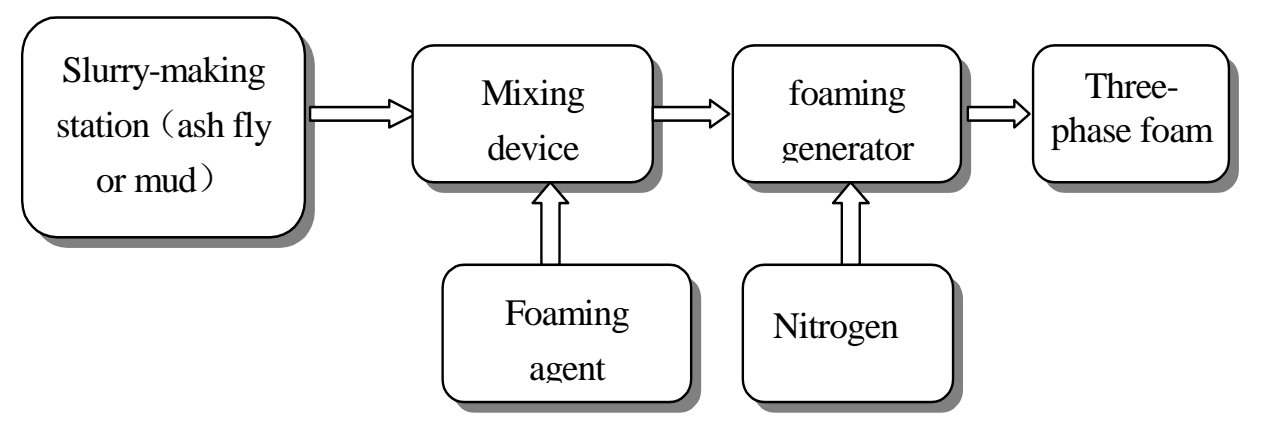

Fig.1. Producing flow chart of three-phase foam. 
The parameters of three phase foam had been studied in the laboratory. Net-discal was adopted as testing device. The developed foaming agent (the content of active matter is 92\%) was compounded by two surfactants with 1:1 in mass match. Figure.2 shows that foaming ability almost reaches the best when the concentration of foaming agent is $0.2 \%$.

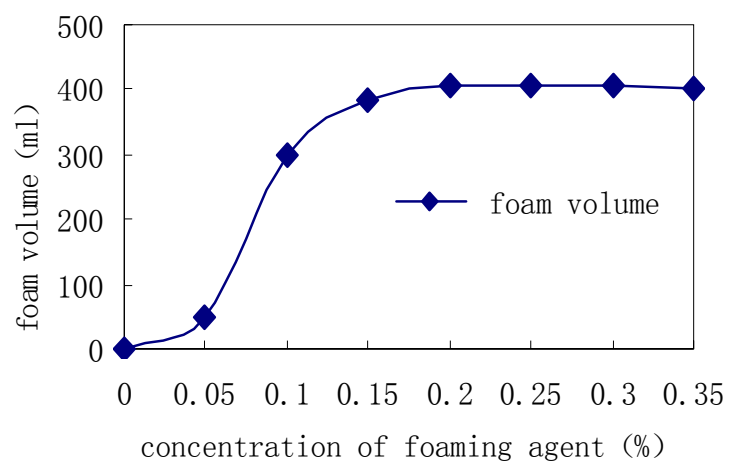

Fig.2. Relation between the foaming ability and the concentration of foaming agent.

The slurry concentration has a great effect on the foaming ability of foaming agent as shown in Fig. 3. When the slurry concentration is $20 \% \sim 50 \%$, or the ratio of ash to water is between $1 / 4$ and $1 / 2$, the foaming ability is the best.

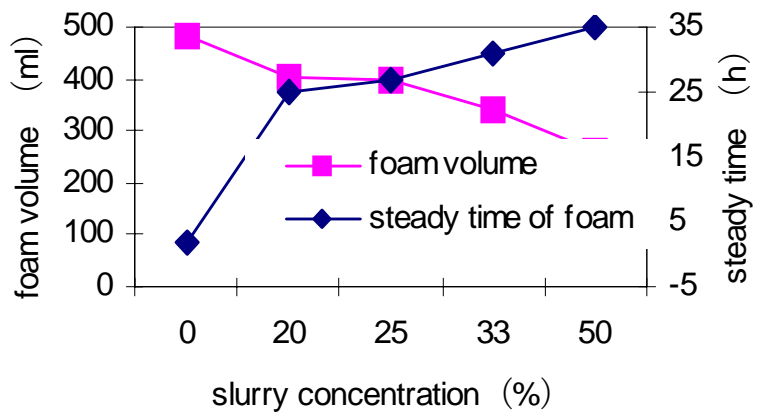

Fig.3. Relation between the foam properties and the concentration of slurry.

\section{THE MECHANISM OF THREE-PHASE FOAM FOR MINE FIRE CONTROL}

\section{Analysis of Chemical Dynamics Theory}

Spontaneous combustion of coal in goaf is a physical and chemical reaction. It was affected by many factors, such as the quantity of float coal, the concentration of oxygen, the temperature of coal and the amount of air leakage. The rate of reaction then can be expressed as:

$V=f\left(C_{1}, C_{2}, \varepsilon, T\right)$ 
On the basis of the Chemical dynamics theory, the rate equations of oxidation reaction and thermal release [3] of coal were set up. Oxidation reaction of coal can be expressed as:

$$
\text { coal }+\mathrm{O}_{2} \rightarrow \text { production }+Q
$$

According to the law of mass conservation: at determinate temperature condition, the rate of chemical reaction is the function of the reactant concentration. Considered the whole ratio in goaf, the reactive rate of spontaneous combustion of coal can be expressed as:

$$
\mathrm{V}=\mathrm{k} \varepsilon \mathrm{C}_{1}^{\mathrm{m}} \mathrm{C}_{2}^{\mathrm{n}}
$$

A great deal of previous experiments showed that the reactive rate was influenced by temperature, so did spontaneous combustion of coal. For example, under normal temperature, the rate could increase $2 \sim 4$ times when temperature was enhanced $1^{\circ} 0$ degrees. In 1889, an equation was put forward by Arrhenius [5]:

$$
k=k_{0} \exp (-E / R T)
$$

The equations of (3) and (4) were combined to form a new equation, that is:

$$
V=k_{0} \varepsilon C_{1}^{m} C_{2}^{\mathrm{n}} \exp (-E / R T)
$$

Then, the rate of thermal release in oxidation reaction can be expressed as:

$$
q=V Q=Q k_{0} \varepsilon C_{1}^{m} C_{2}^{\mathrm{n}} \exp (-E / R T)
$$

Therefore, if the concentration of $\mathrm{C}$ and $\mathrm{O}_{2}$, the whole ratio(r) and the temperature (T) of coal could be reduced, the rate of thermal release and oxidation reaction of coal could be reduced greatly. So the mine fire could be prevented effectively.

\section{Mechanism of Three-Phase Foam for Preventing Spontaneous Combustion of Coal}

\section{Enveloping Air Leakage Passages and Fissures, Isolating Coal from Oxygen}

Because of adopting fully-mechanized top-caving mining method, there is a large amount of coal which was left in goaf. In order to prevent spontaneous combustion of coal, some measures must be taken to isolate coal from oxygen and reduce air leakage. Three-phase foam with the characteristics of enveloping air leakage passage and cranny and isolating coal from oxygen can effectively prevent spontaneous combustion of coal.

After slurry sucks nitrogen gas, three-phase foam comes into being and increases rapidly in volume. After infused into goaf, it can pile up on the higher place, cover the float coal at low or high places and avoid the slurry to flow away from the bottom. The foam is a carrier, it can transport masses of fly ash or mud. These fly ash or mud can jam air leaking spaces so that the coal is isolated from oxygen. Besides, three-phase foam 
contains solid materials such as ash fly ash or mud. Because these materials are part of the surface membrane of foam, they can keep the stability of the foam for a longer time. In addition, even if the foam ruptures, the fly ash or mud with viscosity can cover the float coal uniformly and prevent the coal from oxidation effectively.

In order to study the sealing effect of three-phase foam, testing points were distributed at the distance away the center place of working face. Air leakage intensity can be calculated by the distribution of oxygen concentration. Figure 4 shows that the sealing effect of three-phase foam is remarkable.

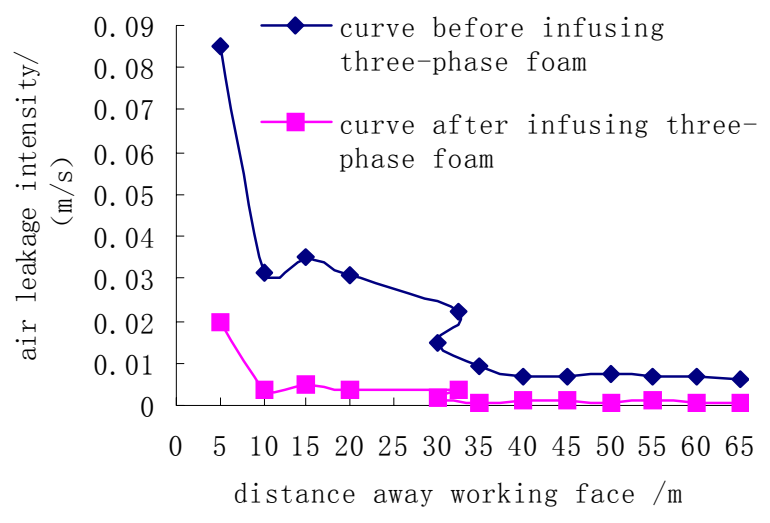

Fig.4. Sealing effect of three-phase foam.

\section{Absorbing Heat and Lowering the Temperature of Coal}

The above equations showed that the rate of oxidation reaction and thermal release would increased if the temperature of coal and its surroundings rose. One reason of spontaneous combustion of coal is the accumulation of heat which is produced by oxidation reaction. Accumulation of heat makes the temperature of coal and its surroundings rise. The speed of the temperature rising is decided by the thermal production of oxidation reaction and the thermal release. The heat is accumulated easily because of the bad thermal release condition in goaf, so the temperature of coal and its surroundings rises and rate of oxidation reaction is quickened. Finally, it results in spontaneous combustion of coal. Water and solid noncombustible in three-phase foam are with very low temperature, so they can absorb much heat to cool coal and its surroundings.

When the thermal delivery reached to balance, the quantity of heat absorbed by slurry can be expressed as following equation:

$Q_{1}=M_{1} c_{p}\left(T_{2}-T_{1}\right)$

The amount of heat absorbed by three-phase foam is vast because of higher specific heat of slurry contained in the foam, the specific heat of slurry is about $5.68 \mathrm{~kJ} /(\mathrm{kg} \cdot \mathrm{K})$. 
At the same time, large amount of heat absorbed during evaporation of water can be expressed as follows when the temperature of ambience exceeds $100^{\circ} \mathrm{C}$ :

$\mathrm{Q}_{2}=\mathrm{M}_{2} \gamma$

The evaporation heat of water is very vast, for example, when $\mathrm{P}=0.1 M P_{a}, \quad T=20{ }^{\circ} \mathrm{C}$, the amount of evaporation heat is $2453 \mathrm{~kJ} / \mathrm{kg}[6,7]$.

Therefore, after infused into goaf, three-phase foam could absorb much heat and cool coal and its surroundings to prevent spontaneous combustion effectively.

\section{Increasing the Humidity of Coal, Preventing Chain Free Radicals}

The developed foaming agent, which is composed of several surfactants, plays two roles in mine fire control. On one hand, it is a excellent inhibitor which can effectively prevents the free radicals from forming and reacting between coal and oxygen [8]; On the other hand, it can improves the characteristic of coal, so coal humidity is greater by sucking much water. Generally, if the water contains foaming agent, the coal could absorb water more than 4 to 6 times. In addition, because of containing foaming agent, a water membrane shaped on the surface of coal could isolates coal from oxygen $[9,10]$.

\section{Reducing Oxygen in Goaf, Restraining the Oxidation and Asphyxiating the Self-Ignited Coal}

The above equations showed that the rate of oxidation reaction and thermal release will accelerate if oxygen is enough. So the concentration of oxygen in goaf should be reduced. If it is taken as the gas phase in three-phase foam, the nitrogen encapsulated in the foam can stay longer in goaf. It can fully play the role in asphyxiating a mine fire. When the foam ruptures, the nitrogen can permeate the whole goaf and make the space keep in the incombustible state. If three-phase foam is infused into goaf continuously, the concentration of oxygen can be reduced less than $5 \%$ in the areas. So the spontaneous combustion of coal can be extinguished or prevented because of lack of oxygen.

\section{APPLICATION}

\section{Brief Introduction of Mine and Working Face}

Daxing coal mine, built in 1980 by China government and put into production in Nov 1990, is the biggest mine in the northeast of china. It belongs to TieFa Mining Group and lies in the southwest of TieFa mine field of LiaoNing province of China.

The $\mathrm{N}_{2} 703$ working face is located at the middle of $\mathrm{N}_{2}$ mining area. The length of intake and return lane are 1411 meters and 1431 meters respectively, the declining width of working face is 160 meters, the area of the whole working face is $227360 \mathrm{~km}^{2}$. The height of coal seam is 5.60 9.88 meters, and the average height is 7.81 meters. The exploitable reserves of the working face are $2379.4 \mathrm{kt}$. The designed mining efficiency is $85 \%$ and the slope of the working face is $15 \sim 25$ degrees. The air leakage is serious because of lots of faults and fissures in the coal seam. The coal seam is prone to spontaneous combustion and the ignition period is 1-3 months, with the shortest ignition period is only 18 days. 


\section{Process of Application}

The $\mathrm{N}_{2} 703$ working face was mined on September 22, 2004. From September 22 30, the velocity of mining is only 1.2 meters per day, and mining was stopped 6 days in the National Day. After the National Day, the velocity of mining reached to 4.2 meters per day. When the working face advanced 90 meters, a lot of CO appeared on Oct. 25 and $\mathrm{C}_{2} \mathrm{H}_{4}$ appeared on Oct.26 in $\mathrm{N}_{2} 703$ working face. But the high temperature place could not be found out. Three-phase foam which was composed of mud, nitrogen and waste water was adopted as the main material to prevent spontaneous combustion of coal. The mass ratio of mud and water in the slurry is $1: 4$, the flux of slurry and nitrogen are $15 \sim 20 \mathrm{~m}^{3} / \mathrm{h}$ and $600 \mathrm{~m}^{3} / \mathrm{h}$ respectively, and the mass proportion of foaming agent is $0.2 \%$. Because of downwards mining of the inclining working face, sand walls were shaped at point 1 and 3 in order to prevent the foam from flowing to the working face, then a great deal of three-phase foam was infused into goaf at point 2 and 4 continuously, it lasted 7 days. The distributions of sampled points and infused points were shown in Fig.5.

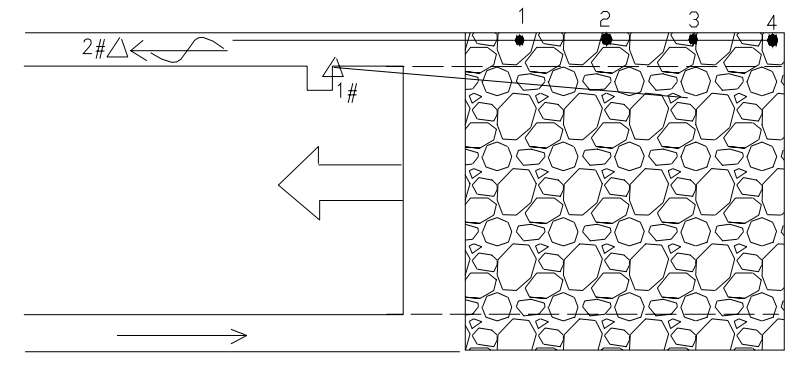

1, 3 exit of grouting sand pipe; 2, 4 exit of infusing three-phase foam pipe; 1\# sampled point connecting goaf; 2\# sampled point in return laneway

Fig.5. Sketch map of sampled points and grouting points distribution.

\section{Effect of Application}

If grouting slurry was adopted to prevent spontaneous combustion of coal, there would be two disadvantages. One was that the slurry grouted into goaf would flow into the intake laneway and the working face along slope or small channel formed by the slurry, so the mining would be interrupted, environment underground destroyed and a lot of slurry wasted; The other was that the slurry could not reach to the fire area and the top fire in goaf, the effect of preventing fire wasn't perfect. Three-phase foam avoided above shortages and enhanced the efficiency of mine fire control. During Oct. 30 to Nov. 5, about 672 tons mud and 2600 tons waste water had been infused into the goaf, but no slurry flowed out. Three-phase foam seen from backside of bracket proved that the whole goaf had been filled with three-phase foam and the fire areas which occurred at higher or uncertain points had been covered by it. Consequently, the fire was controlled effectively.

The change of $\mathrm{CO}$ in 1\# and 2\# were showed in Fig. 6 and Fig. 7 respectively, and the change of oxygen and temperature in goaf are showed in Fig. 8 and Fig. 9. 


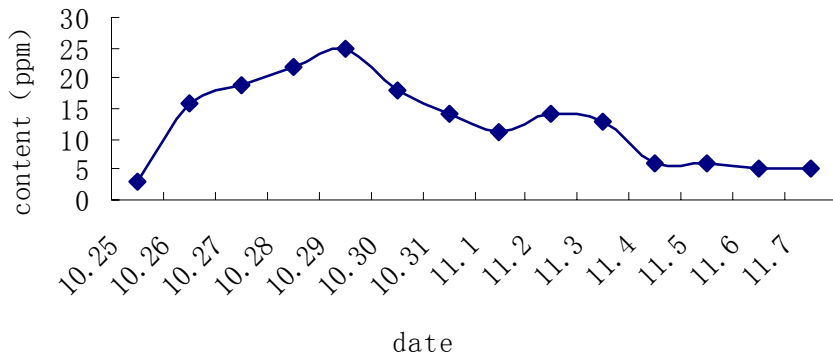

Fig.6. Change of CO in return laneway.

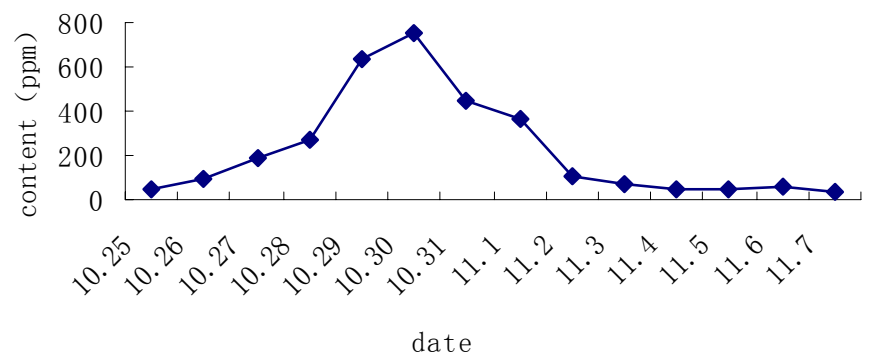

Fig.7. Change of $\mathrm{CO}$ in goaf.

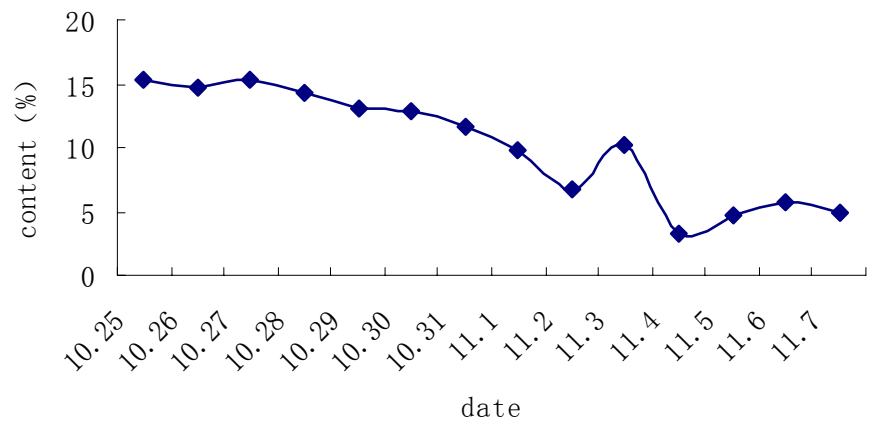

Fig.8. Change of $\mathrm{O}_{2}$ in goaf.

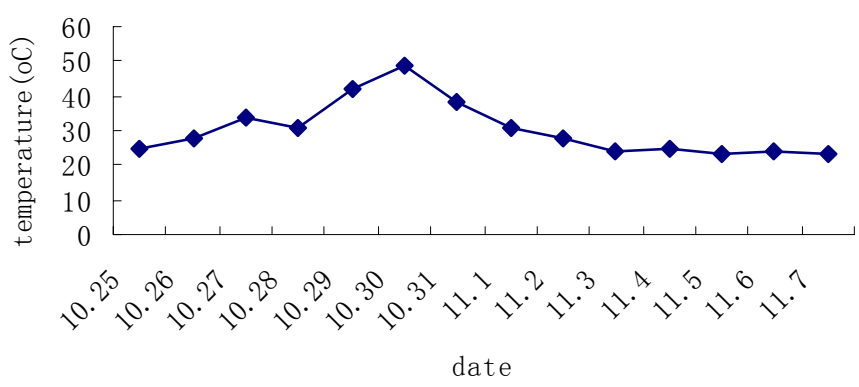

Fig.9. Change of temperature in goaf. 
From the four charts, the conclusion could be drawn that the widely uncertain fire areas had been extinguished, the concentration of $\mathrm{CO}$ in return channel and goal had reduced obviously, and the concentration of oxygen and the temperature in goaf had fallen when three-phase foam was infused abundantly. The results indicated that three-phase foam successfully prevented the spontaneous combustion of coal at $\mathrm{N}_{2} 703$ working face in Daxing Coal Mine.

\section{CONCLUSION}

As a new technology, three-phase foam is especially effective dealing with spontaneous combustion of coal in large area goaf and in slope and downward working face. Threephase foam widely covers coal and piles up in goaf, it can play important role in preventing lower or higher coal in goaf. It makes use of the all-around capability of solid, liquid and gas to prevent mine fire. In other words, the fly ash or mud can cover the combustible, the nitrogen can inert it, the water can cool it, and the foaming can restrain the chain free radicals. Three-phase foam successfully prevented fire in goaf at $\mathrm{N}_{2} 703$ working face and ensured the safe exploitation. The result indicated that the effect of three-phase foam for mine fire control is remarkable.

\section{ACKNOWLEDGEMENTS}

The Supports of the National Natural Science Foundation of China (50274068) and of the Research Fund for Doctoral Program of Higher education (20020290001) are deeply appreciated.

\section{REFERENCE}

[1] Wang Shengshen and Zhang GuoShu, "Prevention of Mine Fire," China University of Mining and Technology Press, 1990, pp. 20-27.

[2] Wang D M, Li Z H, Qin B T, et al., "Development of a Non-Pollution Material of Environmental Protection for Mine Fire Control," Journal of China University of Mining \& Technology, 2004, 33(2):205-208.

[3] Deming Wang, Botao Qin, Xiaoyu Liang, et al., "A New Approach of ThreePhase Foam in Controlling Mine Fire,” Ming Science and Technology $\left(5^{\text {Th }}\right)$, 2004, pp. 159-163.

[4] Qin Botao, Li Zenghua, Wang Deming, et al., "Experiment Study on the Additive of Three-phase Foam for Fire Extinguishment and Prevention," Journal of Liaoning Technical University, 2003, 22(4):467-469.

[5] Du Wenfeng, "Fire Control Combustion,” China People Police University Press, 1997, pp. 7-10.

[6] Liu Yingxue and Wu Peiju, "Mechanism and Application of Thick Loess F1uid Pouring for Prevention of Spontaneous Combustion of Residual Coal in Goaf," China Safety Science Journal, 1997, 2(1):36-39.

[7] Liu Yingxue, "Study on the mechanism and application of fresh water pouring for prevention of oxidation and spontaneous combustion of residual coal in goaf,” Journal of China Coal Society, 2002, 27(3), pp. 237-241. 
[8] Xilin Dong, "Experimental Investigation into the DDS-inhibitors to Suppress the Spontaneous Ignition of Coal,” Fire Safety Science, 1997, 6(1):21-26.

[9] Liu Aihua, Wu Chao, and Cai Kangxu, "Study on Function of Plasticity Plaster Slurry for Preventing and Dealing with Coal Spontaneous Combustion,” Fire Safety Science, 2003, 12(4):230-233.

[10] Xu Yanli, “Surfactant Function,” Chemic Industry Press, 2000, pp. 71-75. 